\title{
Correlation between ultrasound-guided percutaneous breast biopsy and diffusion- weighted magnetic resonance imaging of the breast for evaluation of solid breast lesions
}

\author{
Osama Lotfy Alabd', Mohamed Shawky Alwarraky', Doha Maher Taei ${ }^{2}$, Bayan Eid' and Manal Ebraheim Gomaa ${ }^{1,3^{*}}$
}

\begin{abstract}
Background: MRI's role had been increasing in breast imaging. In this study, we evaluated the role of diffusionweighted MRI in correlation with ultrasound-guided percutaneous breast biopsy for diagnosis of solid breast lesions.

Results: Sixty female patients were diagnosed by clinical examination and mammography and planned for ultrasoundguided breast biopsy. Diffusion-weighted MRI was done before the biopsy for results correlation. It was found that the diffusion-weighted MRI was valuable in evaluating solid female breast lesions, showing a sensitivity of $96 \%$, specificity of $91.4 \%$, positive predictive value of $100 \%$, negative predictive value of $97 \%$, and accuracy of $93.3 \% \%$ compared to pathological results.
\end{abstract}

Conclusion: Diffusion-weighted MRI has a great role in evaluating solid breast lesions.

Keywords: Solid Breast lesions, Diffusion-weighted MRI, Ultrasound-guided biopsy, Evaluation

\section{Background}

Breast cancer is the commonest diagnosed cancer between women around the world, and its incidence is increasing. It is considered the fifth cause of death among cancer patients overall, and it is the leading cause of death due to cancer in women [1]. In Egypt, the most common cancer in females is breast and represents $38.8 \%$, then non-Hodgkin's lymphoma which represents $8.5 \%$. Following them, liver and ovary represent $4.6 \%$ and $4.5 \%$, respectively [2].

The exact cause of breast cancer remains unclear, but some risk factors make it more likely. These included age, genetics, a history of breast cancer, dense breast

\footnotetext{
*Correspondence: mibraheim3333@gmail.com

'Department of Diagnostic and Interventional Radiology, National liver Institute-Menoufiya University, Shebin ElKoum, Egypt

${ }^{3} \mathrm{Al}-\mathrm{Haram} \mathrm{Al}$, Giza, Egypt

Full list of author information is available at the end of the article
}

tissue, estrogen exposure and breastfeeding, bodyweight, alcohol consumption, radiation exposure, hormonal treatments, and occupational hazards [3].

Along with early detection, definitive diagnosis is important in the treatment of breast cancer. Diagnostic modalities encompass clinical, radiological, and pathological findings.

Percutaneous core needle biopsy is considered a rapid, sensitive, specific, and less-cost method in diagnoses which give us prognostic information. It decreases the need for surgical biopsy or frozen-section ones. The main importance of histopathological evaluation done from percutaneous core needle biopsy is that it helps us to differentiate benign and malignant lesions and to categorize each group into different subtypes [4].

MRI of the breast is used to help in the diagnosis of both primary and recurrent breast cancers accurately, especially in cases which the diagnosis is indeterminate by mammography and breast ultrasound [5]. 
DWI gives additional information to improve the data obtained from routine breast MRI and thus increases the benefits of imaging in breast cancer management. DWI gives an idea about the microstructure and thus helps in the characterization of different breast lesions [6]

The purpose of this study was to evaluate the role of diffusion-weighted MRI in correlation with ultrasoundguided percutaneous breast biopsy for the diagnosis of solid breast lesions.

\section{Methods}

\section{Patients}

- The study was performed on 60 female patients presented to the intervention and MRI units of the department of diagnostic and interventional radiology and medical imaging.

- Their ages ranged between 37 and 61 years old.

- The patients were referred from outpatient clinics diagnosed as a breast lump.

- The study was conducted from October 2017 to January 2019.

All patients underwent the following:

- History taking

- Complete physical examination: General and local examination

- Mammography: Routine mammographic study in cranio-caudal and medio-lateral oblique views.

- Diagnostic complementary ultrasonography of the breast: All patients were subjected to bilateral breast ultrasound using a linear probe with frequency 5$10 \mathrm{MHz}$ of GE machine, to differentiate solid from cystic lesions.

\section{Inclusion criteria}

- All patients were hepatic with suspected solid breast lesions.

\section{Exclusion criteria}

- Patients with simple or complicated cystic lesions, by US

- Patients contraindicated to MRI

\section{MRI examinations}

- MRI was done for all patients before taking the biopsy.

- Imaging was performed on 1.5-T GE optima MR scanner release 450W, GE medical systems using a dedicated phased-array four-channel breast coil.
Table 1 Distribution of seciodemographic data among studied group

\begin{tabular}{llll}
\hline & \multicolumn{1}{c}{ Mean \pm SD } & Median & Range \\
\hline Age & $49.25 \pm 12$ & 47.50 & $31.00-61.00$ \\
Marital status (Married) & $60(100 \%)$ & \\
\hline
\end{tabular}

\section{Patient preparation}

- Discussion of the whole study technique with the patient was done.

- Dynamic MRI was done; IV line was secured into the patient arm connected to automated power injector filled with gadolinium (Magnivest) that was estimated according to the patient weight (0.1 $\mathrm{mmol} / \mathrm{Kg}$ ).

- The patient lied prone on MRI table with both breasts fitted into the breast coils in a way that the breasts did not touch the coil with no breast folds or kinks associated.

\section{MRI protocols}

- T2-weighted, fat-saturated sequence with TR (5600), TE (59), FOV (270-340), matrix $(320 \times 314)$, slice thickness $(4 \mathrm{~mm})$, and gap $(20 \%=0.8 \mathrm{~mm})$ in axial plane with extension to the axilla

- T1-weighted non-fat-saturated sequence with TR $(8,6)$, TE (4.7), FOV (270-340), matrix $(448 \times 323)$, slice thickness $(1 \mathrm{~mm})$, and gap $(-10 \%=-0.1 \mathrm{~mm})$ in axial plane with extension to the axilla

- Diffusion-weighted echo-planar imaging (EPI) sequence with TR (4800), TE (98), FOV (270-340), matrix $(192 \times 192)$, slice thickness $(4 \mathrm{~mm})$, and gap $(50 \%=2 \mathrm{~mm})$ in axial plane. The $b$ values were 0 , 400 , and 800 with computer-generated ADC map.

- In DWI, multiple ROI technique was used, in a trial to achieve standardized conditions for results analysis and avoiding data contamination by adjacent structures, multiple freehand regions of interest (ROI) with a mean area of $30 \mathrm{~mm} \sim 2$ (ranging from 10 to $50 \mathrm{~mm} \sim 2$ ) were individually placed on the ADC map at the site of the target lesion and the minimum (ADC $\sim$ min), mean (ADC

Table 2 Distribution of the studies patients BIRAD classifications according to Sono-mammography

\begin{tabular}{lll}
\hline & No & $\%$ \\
\hline Mammography/ US & & \\
BIRADS II & 8 & 13.3 \\
BIRADS III & 5 & 8.4 \\
BIRADS IV & 19 & 31.6 \\
BIRADS V & 28 & 46.7 \\
\hline
\end{tabular}


Table 3 Distribution of the Pathological characterization amoung the studies group patients

\begin{tabular}{lll}
\hline Type of pathology & Number & Percentage \\
\hline Malignant & 26 & $43.3 \%$ \\
- IDC II & 4 & $6.7 \%$ \\
- ILC III & 3 & $5 \%$ \\
- Metastatic HCC & 2 & $3.3 \%$ \\
- Undifferentiated Carcinoma & & \\
Benign & 16 & $26.7 \%$ \\
- Fibroadenoma & 4 & $6.7 \%$ \\
- Granuloma & 3 & $5 \%$ \\
- Inflammatory lesions & 2 & $3.3 \%$ \\
- Fibrocystic disease & & \\
\hline
\end{tabular}

$\sim$ mean), and maximum (ADC $\sim \max ) \mathrm{ADC}$ values were calculated. Necrotic or cystic components were avoided.

\section{Image interpretation}

Two radiologists (more than 10 years' experience) with the knowledge of the aim of the study interpreted the MRI images in consensus.

\section{Percutaneous ultrasound-guided breast biopsy Preparation, ultrasound, and positioning}

- We took informed consent from our patients

- Discussion of the procedure's technique, risks, and benefits

- Good position of the patient to obtain the best access to the lesion, this is usually done by elevating and flattening the breast. We may need to put a foam wedge behind the shoulder of the same side to make the patient oblique and bring the breast toward midline.

- Obtain images with color Doppler to evaluate the lesion and nearby structures or vessels.

\section{Devices}

- We used a 14-gage true cut biopsy needle with 10$\mathrm{cm}$ length.

\section{Local anesthetic}

Table 4 Distribution of MRI diffusion among studied group

\begin{tabular}{lll}
\hline MRI diffusion & No & $\%$ \\
\hline Facilitated & 24 & 40 \\
Mixed & 3 & 5 \\
Restricted & 33 & 55 \\
\hline
\end{tabular}

Table $\mathbf{5}$ The relation of the type of diffusion and the pathological type

\begin{tabular}{llllll}
\hline Type of pathology & $\begin{array}{l}\text { Restricted } \\
\text { and mixed }\end{array}$ & Percentage & $\begin{array}{l}\text { Type of } \\
\text { pathology }\end{array}$ & Faciltated & Percentage \\
\hline - IDC II & 26 & $43.3 \%$ & - Fibroadenoma & 16 & $26.7 \%$ \\
- ILC III & 4 & $6.7 \%$ & $\begin{array}{l}\text { - Inflammatory } \\
\text { lesions }\end{array}$ & 2 & $3.3 \%$ \\
$\begin{array}{l}\text { - Inflammatory } \\
\text { lesions }\end{array}$ & 1 & $1.7 \%$ & $\begin{array}{l}\text { - Fibrocystic } \\
\text { disease }\end{array}$ & 2 & $3.3 \%$ \\
- Metastatic HCC & 3 & $5 \%$ & - Granuloma & 4 & $6.7 \%$ \\
$\begin{array}{c}\text { - Undifferentiated } \\
\text { Carcinoma }\end{array}$ & 2 & $3.3 \%$ & & & \\
\hline
\end{tabular}

- Cleaned the skin with povidone-iodine to disinfect it

- Put sterile cover to the transducer

- Local anesthetic was injected using Lidocaine $1 \%$.

- Introducer and needle advancement

- A small skin incision was made at the entry site using blade scalpel to facilitate appropriate introduction of the needle.

- The needle was advanced and was simultaneously moved with the transducer for good visualization and better position.

- When the position was appropriate, we fired the needle. Many cores were sampled from different views and in the same incision.

\section{Sampling}

- Four to 6 cores were sampled for each patient.

- We put specimens into a specimen jar which has a $10 \%$ formaldehyde solution.

\section{Post-biopsy care}

- Pressure was applied to the site of biopsy for at least $5 \mathrm{~min}$ to reach hemostasis. Then, sterile bandage strips were put over the incision.

- Analgesic in cases of pain was advised to our patients

Table 6 The relation of the type of diffusion and the pathological type

\begin{tabular}{llll}
\hline Type of pathology & $\begin{array}{l}\text { Restricted and } \\
\text { mixed }\end{array}$ & $\begin{array}{l}\text { Type of } \\
\text { pathology }\end{array}$ & Facilitated \\
\hline - IDC II & 26 & - Fibroadenoma & 16 \\
- ILC III & 4 & $\begin{array}{l}\text { - Inflammatory } \\
\text { lesions }\end{array}$ & 2 \\
$\begin{array}{l}\text { - Inflammatory } \\
\text { lesions }\end{array}$ & 1 & $\begin{array}{l}\text { - Fibrocystic } \\
\text { disease }\end{array}$ & 2 \\
- Metastatic HCC & 3 & - Granuloma & 4 \\
$\begin{array}{l}\text { - Undifferentiated } \\
\text { carcinoma }\end{array}$ & 2 & & \\
\hline
\end{tabular}




\section{Statistical analysis}

The collected data were tabulated. Using a statistical program called SPSS (Statistical Package for the Social Science Software) to analyze them, the following was done:

- The qualitative data were expressed in numbers and percentages.

- It was important to calculate sensitivity, specificity, positive predictive value, negative predictive value, and accuracy of DWI MRI results compared to pathological results of the solid breast lesions.

- We used tests of significance.

- Using Student $t$ test, Chi-square test, and ROC curve (receiver operating characteristic curve)

\section{Results}

Our study was done on 60 patients; all of them were married and their ages ranged between 37 and 61 years old (Table 1). Clinical examination, mammography, and ultrasonography were done to select cases with solid breast lesions. Patients were planned for ultrasound-guided breast biopsy. Diffusion-weighted MRI was done before the biopsy for results correlation.

By sono-mammography, 8 patients had criteria of BIRADS II, 5 of BIRADS III, and 19 of BIRADS IV, and 28 show BIRADS V (Table 2).
Pathological characterizations were obtained for all 60 lesions by histopathology. Some of these patients were BIRAD II with high-risk family history of breast cancer and they (or the surgeon) requested biopsy. We noted that the infiltrating ductal carcinoma was the most frequent malignant histological type (43.3\%), while the most frequent benign solid lesion was fibroadenoma (18.3\%). There were three cases of breast tissue that showed inflammatory lesion signs with no pathological tumor evidence, one of them had a restricted diffusion which was considered a false-positive result. In (Table 3), we described the pathological findings completely.

By diffusion-weighted MRI, 24 cases $(40 \%)$ showed facilitated diffusion, 33 cases (55\%) showed restricted diffusion, and three cases showed mixed diffusion (5\%) as seen in (Table 4).

The relation of the type of diffusion and the pathological type was described in (Table 5).

In Table 6, we described accuracy of DWI of examined breast solid lesions compared to pathological finding.

From Table 6, we found that the diagnostic accuracy at cutoff value 1.5 was $93.3 \%$. Sensitivity was $96 \%$ (CI 95\% 92-100\%), whereas specificity was 91.4\% (CI 95\% $88.2-94.6 \%$ ). Also, we found $100 \%$ positive predictive value and $97 \%$ negative predictive value.

Figure 1 describe the correlation between DWI and pathological finding. $P$ value and ROC curve between results of DW MRI and pathological results was $P>0.05$

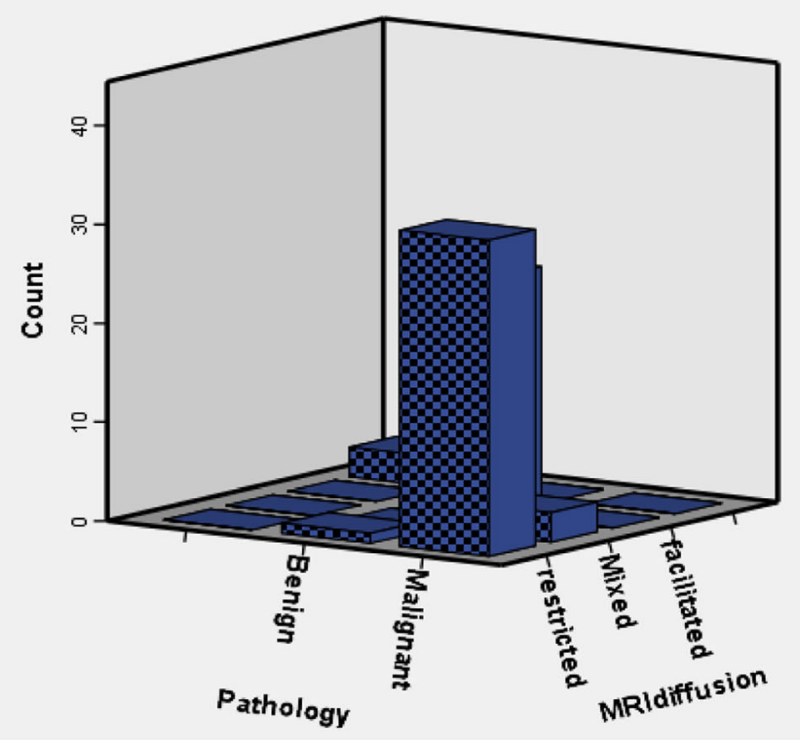

Fig. 1 Correlation between DWI and pathological finding 


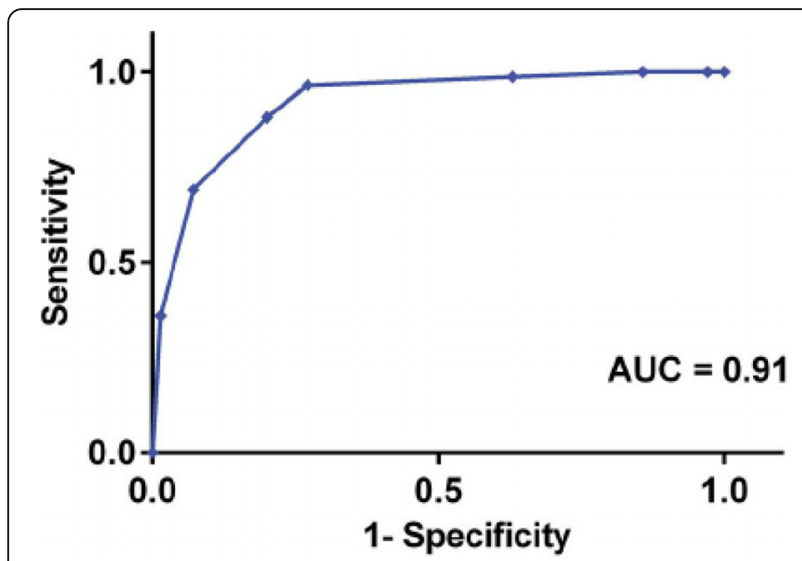

Fig. 2 ROC curve showing the correlation between DWI and pathological finding that means non-significant difference, which confirms high sensitivity and specificity of DW MRI (Fig. 2).

\section{Cases}

Figures 3, 4, and 5 represent a sample of selected patients of our study, each figure for one case.

\section{Discussion}

Nowadays, MRI of the breast has become an important investigation for breast focal lesions characterization. Many researches described this importance in practice [7].

Our study included 60 patients, with mean age of 49 years (their ages ranged between 37 and 61 years old). This is consistent with El-Wakeel et al.'s study as the ages of the patients included in his study ranged between 30 and 65 years. The age of patients was younger in cases with benign lesions and ranged between 30 and 55 years with a mean age of 40.2 years. The age of patients was older in cases with malignant lesions, ranging
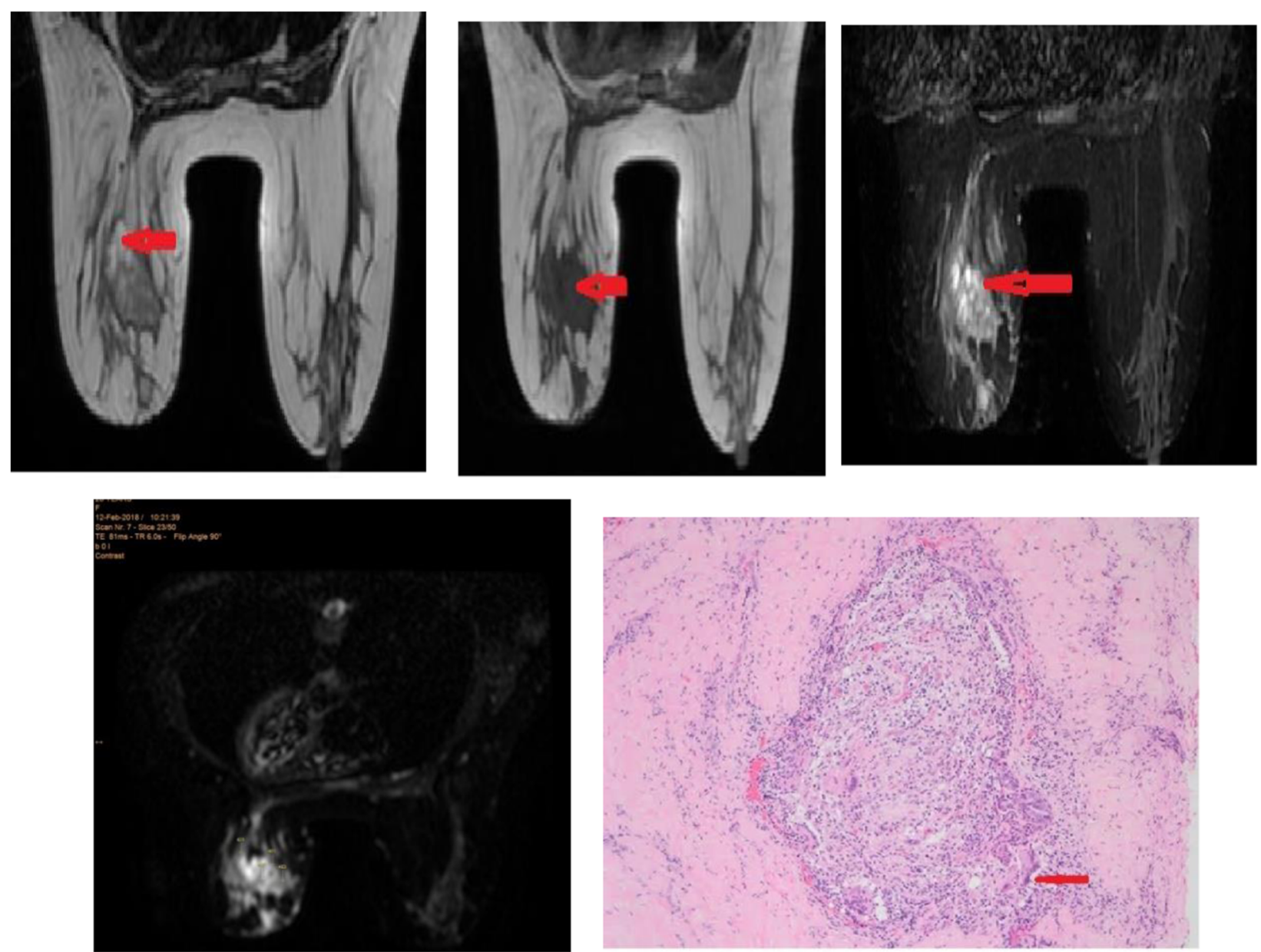

Fig. 3 28-year-old female patient with negative family history presented with left retroareolar lump. The mass shows intermediate signal on T2, low signal on T1, and heterogeneous bright signal on STIR. The solid parts of the mass show restricted diffusion and ADC values range from 1.1 to $1.2 \times 10^{-3} \mathrm{~mm}^{2} \mathrm{~s}$. The pathological diagnosis is inflammatory lesion, negative for malignancy 

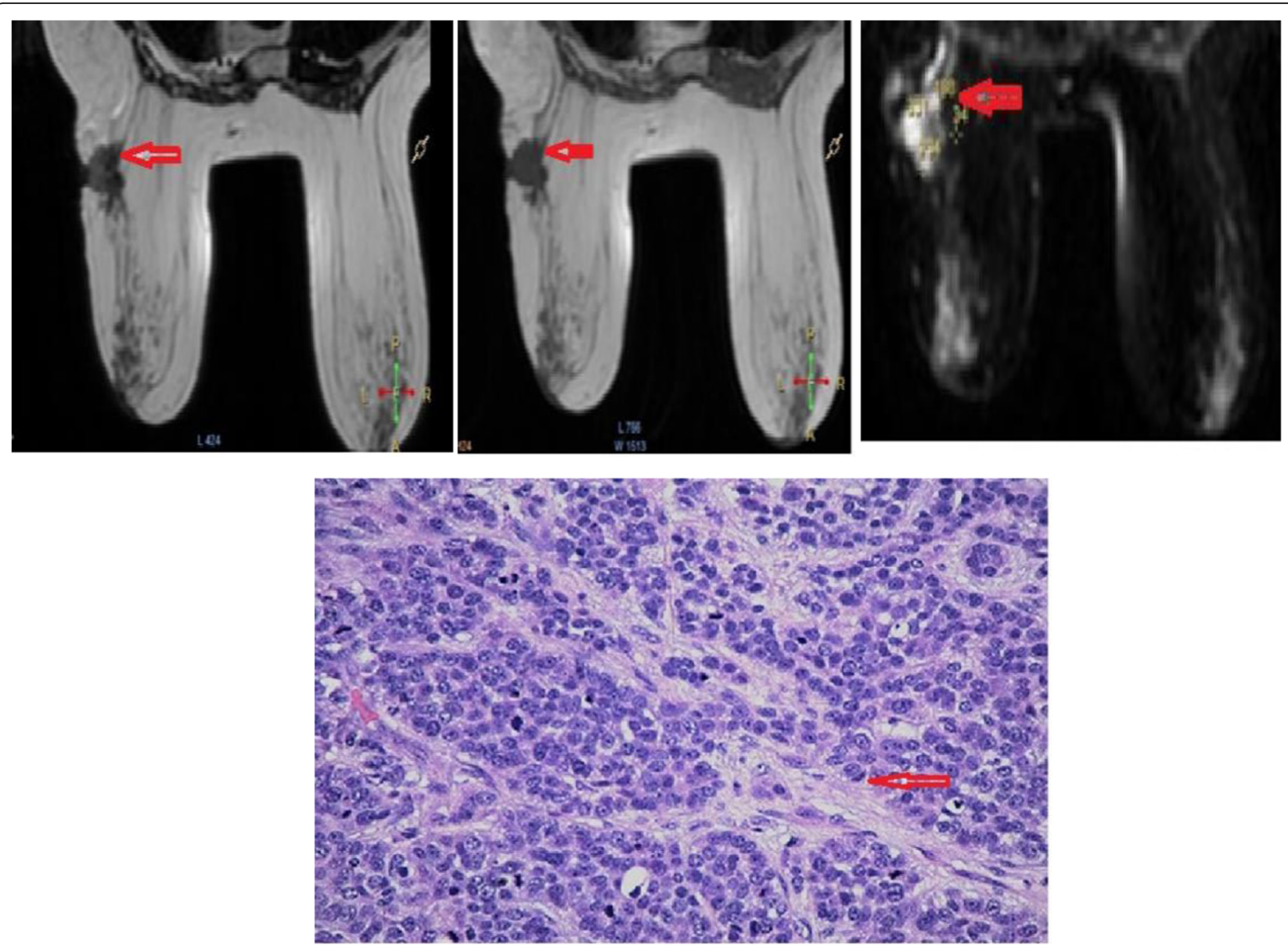

Fig. 4 80-year-old female patient presented with left upper outer quadrant breast lump. The mass displays low signal on T2 and on T1 with bright signal on STIR. It shows restricted diffusion and ADC values range between 0.4 and $0.9 \times 10^{-3} \mathrm{~mm}^{2} \mathrm{~s}$. Pathological diagnosis is invasive duct carcinoma grade II

between 35 and 62 years with a mean age of 48.4 years. So the incidence of malignant lesions was increased with increased age [8].

Differences in ADC were most dramatic in large, heterogeneous, and non-mass lesions. Some studies have reported that a smaller ROI placed over the most hypointense ADC area may provide better discriminating performance by reflecting the worst pathology within a heterogeneous lesion. On the other hand, whole tumor measurement may allow better reproducibility. Semiautomated ROI selection techniques further show promise to improve efficiency, accuracy, and reproducibility of breast lesion ADC measures [9].

Researches or studies were done for this subject had reported that the mean ADC values of malignant lesions (range 0.95-1.22) were significantly different from benign lesions (1.44-1.67) depending on the $b$ value [10].

Regarding our study, ADC values of the solid breast lesions were moderately higher than those recorded in the literature. That may be due to usage of lower $b$ value in our protocol ( $b$ values $0-800 \mathrm{~mm} / \mathrm{s}^{2}$ ), while that of the other most studies was $(0-1000)$, this was due to the need to obtain a high signal-to-noise ratio even with a four-channel coil.

- The ADC values of malignant lesions (1.01-1.51; mean 1.29) and that of benign lesions (1.32-2.02; mean 1.67) were highly significant differences $(P<$ 0.001 ). Also, significant differences in diffusion coefficient between malignant lesions and normal breast tissue were reported (mean ADC was approximately 2 in normal breast) [11]. In our study, we did not do this evaluation because we were interested only with solid masses which did not show any normal breast tissue in their histopathology. However, relatively few reports related to our subject found that the possible cause of false-negative results was low cellularity of some 

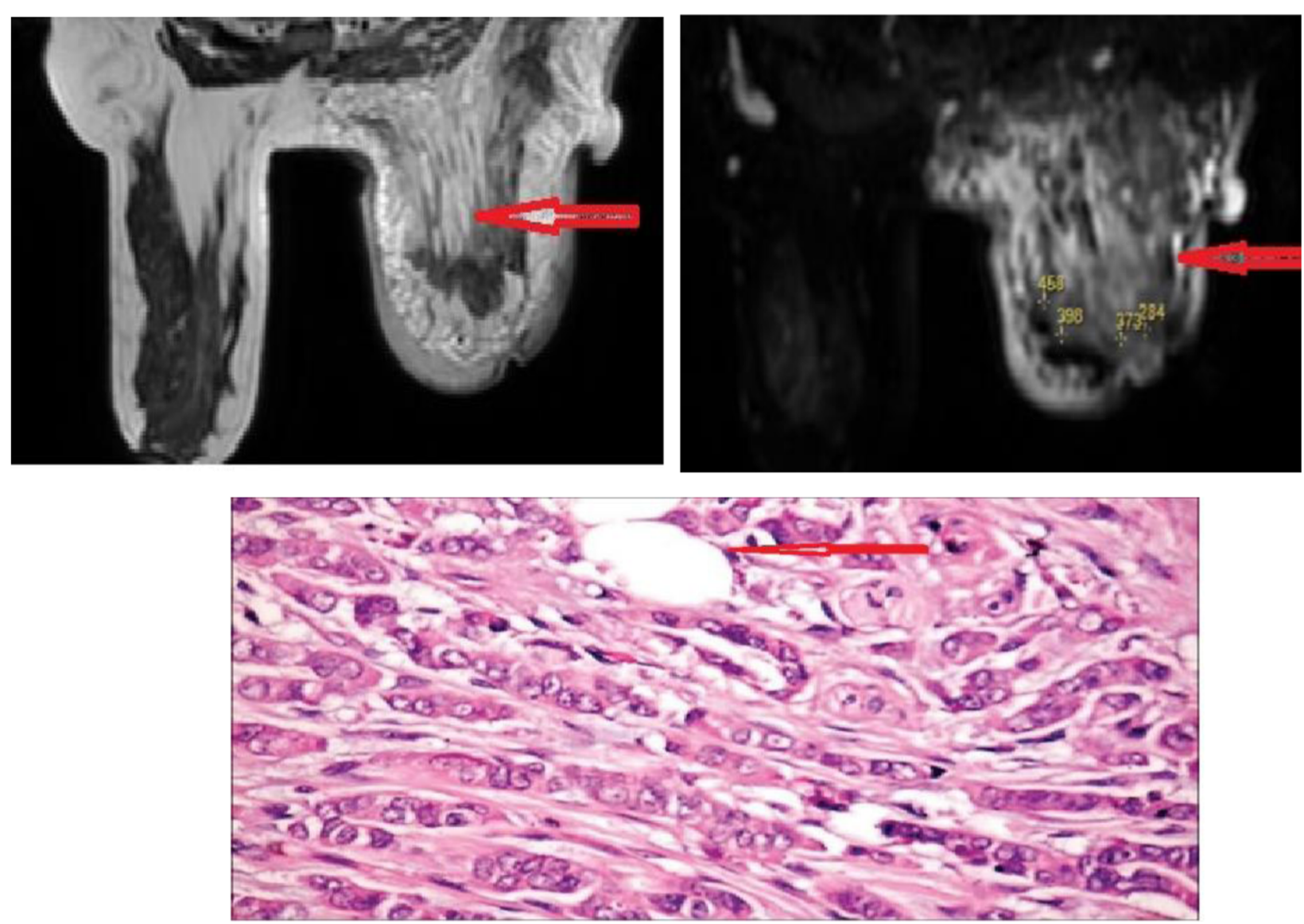

Fig. 5 46-year-old female presented with right breast diffuse swelling with palpable retroareolar lump. Right breast diffuse edema and skin thickening with multiple ill-defined infiltrative lesions displaying high signal on T2. The lesions show restricted diffusion. ADC values range between 0.7 to $1.3 \times 10^{-3} \mathrm{~mm}^{2} \mathrm{~s}$. The pathological diagnosis is inflammatory carcinoma

histopathological types such as mucinous, lobular, apocrine, and scirrhous carcinomas [12].

While false-positive DWI findings were found in some of the benign focal lesions such as fibrocystic mastopathy and intraductal papilloma that is mainly due to higher cellularity of these lesions, fibrocystic mastopathy showed the lowest ADC values (1.45) were recorded for a case in previous studies [13].

In our report, we were unable to perform a valuable statistical evaluation of the possible correlation between $\mathrm{ADC}$ and histopathology due to the small number of patients and the qualitative distribution of malignant lesions. This correlation had been supported by some authors (Nasu et al., 2008) but refused by others [14].

On the other hand, our study had some limitations, because we selected only patients with hepatic diseases who had solid lesions deserving investigation with breast MRI, and only those requiring pathological characterization. Our series did not contain findings with a low index of suspicion, the presence of which might have reduced the diagnostic performance of DWI.

\section{Summary}

The potential value of DWI for improving the diagnosis, management, and follow-up of breast cancer patients is growing. This supplemental MRI technique is increasingly being included in breast MRI protocols. DWI has a short acquisition time, it is widely available with most of commercial MR scanners, and the contrast agent injection is not needed.

However, in some institutions, there are obstacles in routine clinical application DWI of breast related to technical points and need of standardization of imaging approaches. Novel acquisition techniques are under development to overcome commonly encountered image quality issues, and advanced modeling approaches hold potential to further expand the capabilities of DWI as an imaging biomarker. 
Results of prospective multicenter trials will help to establish generalized guidelines, which are needed to facilitate the widespread implementation of DWI for breast imaging.

\section{Conclusion}

From our study, we conclude that DWI is an important diagnostic complement technique for characterizing of solid breast lesions in patients undergoing MRI, due to its relative inexpensiveness and rapidness, even though it is as yet unable to avoid the need for pathological characterization.

\section{Abbreviations \\ MRI: Magnetic resonance imaging; DW MRI: Diffusion-weighted MRl; IDC: Invasive ductal carcinoma; ILC: Invasive lobular carcinoma; HCC: Hepatocellular carcinoma; ADC: Apparent diffusion coefficient; BIRAD: Breast imaging-reporting and data system}

\section{Acknowledgements}

We acknowledge the patients who accepted using their data and the radiology staff in the Department of Diagnostic and Interventional Radiology, National liver Institute—Menoufiya University.

\section{Authors' contributions}

OL: Gave the idea of the research, determined its main lines, and reviewed the research. MS: Put study design. DM: Responsible for the pathological part in the research. BE: Radiology resident who collected the data. MI: Reviewed the master sheet and wrote the paper with revision. All authors read and approved the final manuscript.

\section{Funding}

This study had no funding from any resource.

\section{Availability of data and materials}

The datasets used and/or analyzed during the current study are available from the corresponding author on reasonable request. You could contact with Dr. Manal Ibraheim.

\section{Ethics approval and consent to participate}

All study procedures were conducted in accordance with the Declaration of Helsinki and were approved by the ethical committee of the National Liver Institute/Menoufiya University, Egypt. The Ethics committee reference number is NLI IRB protocol number 00160. All patients included in this study gave us written consent to participate and all were adults, so no parental consent was taken.

\section{Consent for publication}

All patients included in this research gave written informed consent to publish the data contained within this study.

\section{Competing interests}

The authors declare that they have no competing interests.

\section{Author details}

${ }^{1}$ Department of Diagnostic and Interventional Radiology, National liver Institute-Menoufiya University, Shebin ElKoum, Egypt. ${ }^{2}$ Department of Clinical Pathology, National liver Institute-Menoufiya University, Shebin ElKoum, Egypt. ${ }^{3} \mathrm{Al}-\mathrm{Haram} \mathrm{Al}$, Giza, Egypt.

Received: 29 August 2019 Accepted: 23 April 2020

Published online: 18 June 2020

\section{References}

1. De Santis CE, Ma J, Goding Sauer A, Newman LA, Jemal A (2017) Breast cancer statistics, 2017, racial disparity in mortality by state. CA Cancer J Clin. 67:439

2. Amal S. Ibrahim, Hussein M. Khaled, Nabil Nh Mikhail. (2014) : Cancer Incidence in Egypt- Results of the National Population-Based Cancer
Registry Program. J Cancer Epidemiology, Volume 2014, Article ID 43797: page 11-28.

3. Pike MC, Spicer DV, Dahmoush L (1993) Estrogens, progestogens, normal breast cell proliferation, and breast cancer risk. Epidemiol Rev 15(1):17-35

4. Seo J, Kim SM, Jang M, La Yun B, Lee SH, Kim E-K, Kang E, Park SY, Moon WK, Choi HY, Kim B (2017) Ultrasound-guided cable-free 13-gauge vacuumassisted biopsy of non-mass breast lesions. PLoS One. 12(6):e0179182

5. Zheng H, Wu X, Roelle S, Chen C, Schiemann WP, Lu Z-R (2017) Targeted gadofullerene for sensitive magnetic resonance imaging and riskstratification of breast cancer. Nat Commun 8:692

6. Partridge SC, Amornsiripanitch N (2017) DWI in the assessment of breast lesions. Top MagnReson Imaging. 26(5):201-209

7. Imamura T, Isomoto I, Sueyoshi E, Yano H, Uga T, Abe K, Hayashi T, Honda S, Yamaguchi T, Uetani M (2010) MagnReson Med Sci. 9(4):217-225

8. Elwakeel AM, Omar SF, Bayoumy AR (2018) Role of magnetic resonance imaging in differentiation of benign and malignant breast lesions. Menoufia Med J 31:502-507

9. Yoshikawa MI, Ohsumi S, Sugata S et al (2008) Relation between cancer cellularity and apparent diffusion coefficient values using diffusion-weighted magnetic resonance imaging in breast cancer. Radiat Med 26:222-226

10. Bammer R (2003) Basic principles of diffusion-weighted imaging. Eur J Radiol 45:169-184

11. Matsuoka A, Minato M, Harada M et al (2008) Comparison of 3.0- and 1. 5tesla diffusion-weighted imaging in the visibility of breast cancer. Radiat Med 26:15-20. https://doi.org/10.1007/s11604-0070187-6

12. Schmithorst VJ, Dardzinski BJ, Holland SK (2001) Simultaneous correction of ghost and geometric distortion artifacts in EPI using a multiecho reference scan. IEEE Trans Med Imaging 20:535-539

13. Kuroki-Suzuki S, Kuroki Y, Nasu K et al (2007) Detecting breast cancer with non-contrast MR Imaging: combining diffusion-weighted and STIR imaging. Magn Reson Med Sci 6:21-27

14. Kuroki Y, Nasu K, Kuroki-Suzuki S et al (2004) Diffusion-weighted imaging of breast cancer with the sensitivity encoding technique: analysis of the apparent diffusion coefficient value. MagnReson Med Sci 3:79-85

\section{Publisher's Note}

Springer Nature remains neutral with regard to jurisdictional claims in published maps and institutional affiliations.

\section{Submit your manuscript to a SpringerOpen ${ }^{\circ}$ journal and benefit from:}

- Convenient online submission

- Rigorous peer review

- Open access: articles freely available online

High visibility within the field

- Retaining the copyright to your article

Submit your next manuscript at $\boldsymbol{\nabla}$ springeropen.com 